\title{
Treatment of invasive fungal infections in clinical practice: a multi-centre survey on customary dosing, treatment indications, efficacy and safety of voriconazole
}

\author{
Jörg J. Vehreschild · Angelika Böhme - Dietmar Reichert · \\ Michael G. Kiehl · Dorothee Arenz · Karen Pankraz • \\ Matthias Kochanek · Andrew J. Ullmann · Oliver A. Cornely
}

Received: 17 July 2007/Revised: 22 September 2007/Accepted: 1 October 2007/Published online: 21 February 2008

(C) The Japanese Society of Hematology 2008

\begin{abstract}
Invasive fungal infections are frequent and often deadly complications in patients with malignant hematological diseases. Voriconazole is a third generation triazole antifungal with broad activity against most clinically relevant fungal pathogens. Clinical practice often deviates from insights gained from controlled randomized trials. We conducted a multi-centre survey to evaluate efficacy, safety, treatment indications and dosing of voriconazole outside clinical trials. Patients receiving voriconazole were documented via electronic data capturing. An analysis was conducted after submission of 100 episodes from September 2004 to November 2005. Voriconazole was administered for suspected or proven invasive fungal infection (IFI) (57\%), as empirical
\end{abstract}

J. J. Vehreschild · D. Arenz · K. Pankraz · M. Kochanek ·

O. A. Cornely $(\square)$

Klinikum der Universität zu Köln, Klinik I für Innere Medizin, Studienzentrum Infektiologie II,

Kerpener Straße 62, 50937 Köln, Germany

e-mail: oliver.cornely@uni-koeln.de

A. Böhme

Johann Wolfgang Goethe-Universität Frankfurt,

Medizinische Klinik II, Theodor-Stern-Kai 7,

60590 Frankfurt am Main, Germany

D. Reichert

Städtische Kliniken Oldenburg, Dr. Eden-Straße 10,

26133 Oldenburg, Germany

M. G. Kiehl

Klinikum Frankfurt/Oder, Klinik für Innere Medizin, Müllroser Chaussee 7, 15236 Frankfurt an der Oder, Germany

A. J. Ullmann

Johannes-Gutenberg-Universität Mainz, Medizinische Klinik III,

Langenbeckstr. 1, 55101 Mainz, Germany treatment in patients with fever of unknown origin (21\%) and secondary (19\%) as well as primary (3\%) prophylaxis of IFI. Investigators' assessment of fungal infection often diverted from EORTC/MSG 2002 criteria. A favorable response was reported in $61.4 \%$ for suspected or proven IFI and $52.4 \%$ for empirical treatment. Mortality was $15 \%$, $26.7 \%$ of which was attributable to IFI. Breakthrough fungal infections occurred in four $(21.1 \%)$ patients with voriconazole as secondary prophylaxis. Toxicity and adverse events comprised elevated liver enzymes and visual disturbances. Although indications frequently deviated from clinical evidence and legal approval, voriconazole showed efficacy and safety, comparable to major controlled clinical trials. Data from this survey demonstrate the difficulty of putting drugs to their approved use in IFI.

Keywords Antifungals - Aspergillosis - Candidiasis · Fungal infection · Voriconazole · Drug therapy · Prophylaxis

\section{Introduction}

Patients with malignant hematological diseases receiving remission-induction chemotherapy are at a high risk of contracting severe and sometimes lethal invasive fungal infections, especially invasive pulmonary aspergillosis (IPA) [1-4].

Voriconazole follows itraconazole as the second triazole-antifungal agent with an enhanced spectrum of activity against numerous clinically important fungi. This activity is achieved by inhibition of fungal cytochrome P450-mediated 14 $\alpha$-lanosterol demethylase, a key enzyme in ergosterol biosynthesis. Subsequent loss of ergosterol in 
the fungal cell wall and accumulation of $14 \alpha$-methyl sterols are the primary mode of action of voriconazole.

Among the properties of voriconazole are in vitro fungistatic activity against most Candida spp., including those resistant to fluconazole [5-7], fungicidal activity against several Aspergillus spp. [8-10] as well as profound activity against Fusarium spp. [8-13], Scedosporium spp. [14], Cryptococcus spp. [7] and other rare yeasts, molds and dermatophytes, such as Trichosporon spp., Blastomyces spp., Histoplasma capsulatum and Coccidioides immitis [14, 15]. In a controlled clinical trial, voriconazole proved superior efficacy and improved survival when compared with amphotericin B deoxycholate in the treatment of invasive aspergillosis [16]. Voriconazole has been approved by the US Food and Drug Administration (FDA) and European Medicines Agency (EMEA) for treatment of invasive aspergillosis, invasive candidiasis in non-neutropenic patients, esophageal candidiasis as well as serious infections caused by Scedosporium apiospermum and Fusarium spp. in cases refractory to or intolerant of first line treatment [17]. Availability of oral (tablets, suspension) and intravenous preparations along with a favorable safety profile make voriconazole a popular drug among clinicians in cases of suspected or proven invasive fungal infection alike. Voriconazole has become a well-accepted treatment option in probable and proven IFI [18].

Controlled clinical trials are an imperative tool for testing drug efficacy and safety in an idealized study population. To allow comparison between clinical trials, the European Organisation for Research and Treatment of Cancer (EORTC) and the Mycoses Study Group (MSG) have established criteria for the diagnosis of IFIs [21]. These criteria classify IFIs as possible, probable, or proven according to diagnostic test results. Basically, these criteria demand major clinical signs in combination with host factors for a possible diagnosis. For a probable diagnosis, certain microbiological criteria (e.g. serum galactomannan) must be fulfilled, while a proven diagnosis demands histopathological findings or positive culture from a primary sterile site. However, trial results do not always translate into everyday clinical practice. We therefore conducted a multi-centre survey to evaluate efficacy and safety as well as common treatment indications and prescribed dosing of voriconazole outside clinical trials.

\section{Methods}

Participating investigators were asked to document all patients receiving voriconazole via online electronic data capture. Data were collected retrospectively after treatment completion. Collected data comprised demographic information, underlying disease, indication for treatment, earlier antifungal treatment, risk factors for invasive fungal infection, clinical outcome (including results of diagnostic imaging, microbiology, lab results, vital signs and survival), occurrence of adverse events, concurrent medication, and evaluation of response. Treatment outcome was evaluated by the investigator. Data were monitored electronically and manually for plausibility and completeness and queries were raised to the investigators in cases that were unclear or incomplete.

An analysis was conducted after submission of 100 episodes. The objective of the analysis was the evaluation of drug safety and efficacy as well as dosing habits and indications for voriconazole therapy by means of descriptive analysis. All episodes were registered in the period from September 2004 to November 2005. Drug toxicities were evaluated applying common toxicity criteria (CTC) [19].

\section{Results}

One-hundred patient courses from the hematological units of five different centers (43 from Frankfurt am Main, 42 from Oldenburg, 10 from Cologne, 4 from Frankfurt an der Oder and 2 from Mainz) were successfully enrolled in the survey. All relevant data concerning the survey objectives were present. The most frequent underlying disease was hematological malignancy $(94 \%)$. A total of 15 patients underwent stem cell transplantation, 12 of these were allogeneic and 8 showed signs of acute or chronic graftversus-host disease (GvHD). The five patients with other hematological diseases were two patients with aplastic anemia, two with myelodysplastic syndrome and one with osteomyelofibrosis. Almost half of the patients $(N=48)$ were isolated by means of reverse isolation, 27 patients had air conditioning with high-efficiency particulate air filters (HEPA). Only 14 patients were accommodated with no isolation at all (Table 1).

The most common indication for voriconazole treatment was suspected or proven IFI by assessment of the investigator $(N=57), 21$ patients received voriconazole as empirical treatment for an episode of fever of unknown origin (FUO) while considered at risk for an IFI. Other treatment indications were prophylaxis of IFI $(N=22), 19$ of which were considered as secondary prophylaxis after an earlier episode of IFI. On average, treatment duration was 27 days (Table 1). Fifteen patients died during the observation period. Causes of death were severe sepsis with multi-organ failure $(N=6)$, progression of the underlying disease $(N=4)$, progression of IFI $(N=4)$ and severe arrhythmia with cardiac arrest $(N=1)$. The investigator attributed the lethal arrhythmia to hypokalemia several 
Table 1 Patient characteristics at baseline and subsequent voriconazole exposure $(N=100)$

\begin{tabular}{|c|c|}
\hline Age $(\text { years })^{\mathrm{a}}$ & $59(24-84)$ \\
\hline Female & $37(37 \%)$ \\
\hline Mean weight in $\mathrm{kg}( \pm \mathrm{SD})$ & $76.2( \pm 14.7)$ \\
\hline \multicolumn{2}{|l|}{ Underlying disease $^{\mathrm{b}}$} \\
\hline Acute myeloid leukemia & 72 \\
\hline Acute lymphoblastic leukemia & 9 \\
\hline Low grade non-Hodgkin lymphoma & 4 \\
\hline Other hematological malignancy & 9 \\
\hline Other non-malignant hematological disease & 5 \\
\hline Solid tumors & 3 \\
\hline Stem cell transplantation & 15 \\
\hline Unrelated donor & 8 \\
\hline Sibling donor & 4 \\
\hline Autologous & 3 \\
\hline Graft-versus-host disease & 8 \\
\hline \multicolumn{2}{|l|}{ Isolation } \\
\hline Reverse isolation & 48 \\
\hline $\mathrm{HEPA}^{\mathrm{c}}$ & 27 \\
\hline No isolation & 14 \\
\hline LAF & 9 \\
\hline $\mathrm{HEPA}^{\mathrm{c}}+$ reverse isolation & 2 \\
\hline \multicolumn{2}{|l|}{ Treatment indication } \\
\hline Primary prophylaxis & 3 \\
\hline Empirical therapy & 21 \\
\hline Suspected or proven IFI & 57 \\
\hline Secondary prophylaxis & 19 \\
\hline Days on voriconazole $( \pm \mathrm{SD})$ & $26.7( \pm 43.3)$ \\
\hline
\end{tabular}

days after switching antifungal therapy from voriconazole to liposomal amphotericin B.

For the 57 patients receiving voriconazole for treatment of suspected or proven IFI, the lung was the most common site of infection $(N=55)$. Microbiological evidence was obtained in two cases of candidemia, one invasive pulmonary aspergillosis and one Geotrichum capitatum fungemia. All other patients had suspected invasive pulmonary aspergillosis by the investigator's assessment. Frequent risk factors were exposures to dust due to nearby construction sites $(N=47)$, leukopenia $(N=43)$, indwelling central venous catheters $(N=39)$, immunosuppressive therapy $(N=35)$ and mucositis $(N=25)$. The initial daily voriconazole dose averaged $6.8 \mathrm{mg} / \mathrm{kg}$. Almost half of the patients were treated orally from the beginning $(N=27)$. In 21 of the remaining 30 patients, therapy was later switched to oral administration. Treatment success was rated by the investigators as complete or partial
Table 2 Characteristics of patients with suspected or proven IFI by assessment of the investigator $(N=57)$

\begin{tabular}{|c|c|}
\hline \multicolumn{2}{|l|}{ Site of infection ${ }^{\mathrm{a}}$} \\
\hline Lung & $55(96.5 \%)$ \\
\hline Blood (fungemia) & $2(3.5 \%)$ \\
\hline Sinus & $2(3.5 \%)$ \\
\hline CNS & $1(1.8 \%)$ \\
\hline Liver & $1(1.8 \%)$ \\
\hline \multicolumn{2}{|l|}{ Risk factors } \\
\hline Diabetes mellitus & $4(7 \%)$ \\
\hline HIV & $1(1.8 \%)$ \\
\hline Leukopenia $^{\mathrm{b}}$ & $43(75.4 \%)$ \\
\hline Mucositis & $25(43.9 \%)$ \\
\hline Prior IFI & $7(12.28 \%)$ \\
\hline Central venous catheter & $39(68.4 \%)$ \\
\hline Dust exposure & $47(82.5 \%)$ \\
\hline Surgery & $1(1.8 \%)$ \\
\hline Cytarabine & $14(24.6 \%)$ \\
\hline Purine analogues & $7(12.3 \%)$ \\
\hline Steroids & $10(17.5 \%)$ \\
\hline Other immunosuppressant & $4(7 \%)$ \\
\hline Days with fever $( \pm \mathrm{SD})$ & $7.6( \pm 6.54)$ \\
\hline Total days on antibiotic treatment $( \pm \mathrm{SD})$ & $29.3( \pm 18.30)$ \\
\hline Days on voriconazole $( \pm \mathrm{SD})$ & $26.6( \pm 26.76)$ \\
\hline Average initial voriconazole $\mathrm{mg} / \mathrm{kg}$ (range) & $6.8(3.125-13.559)$ \\
\hline \multicolumn{2}{|l|}{ Route of administration } \\
\hline Oral only & $27(47.4 \%)$ \\
\hline Switch to oral & $21(36.8 \%)$ \\
\hline Switch to intravenous & $4(7.0 \%)$ \\
\hline \multicolumn{2}{|l|}{ Outcome $^{c}$} \\
\hline Complete response & $19(33.3 \%)$ \\
\hline Partial response & $16(28.1 \%)$ \\
\hline Stable disease & $11(19.3 \%)$ \\
\hline Progressive disease & $11(19.3 \%)$ \\
\hline Switch to other antifungal & $15(26.3 \%)$ \\
\hline Liposomal amphotericin B & $8(14.0 \%)$ \\
\hline Caspofungin & $5(8.8 \%)$ \\
\hline Other & $2(3.5 \%)$ \\
\hline
\end{tabular}

${ }^{a}$ Super additive because of patients with multiple infection sites

b As defined as less than 1,000 leukocytes/ $\mu 1$

c As assessed by investigator

response in 35 (61.4\%) patients. Disease remained stable in another $11(19.3 \%)$ patients. Progressive disease was diagnosed in the remaining 11 patients (19.3\%). Fifteen (26.3\%) patients were switched to a different antifungal class (Table 2).

An evaluation of the investigators' adherence to EORTC/MSG criteria showed a discrepancy between the softer criteria used in recent clinical trials $[16,20]$ and the official 2002 criteria [21]. While recent trials allowed the 
Table 3 Evidence rating for patients with IFI suspected or proven by the investigator $(N=57)$

\begin{tabular}{lccc}
\hline & $\begin{array}{l}\text { Investigator } \\
\text { assessment }\end{array}$ & $\begin{array}{l}\text { According to } \\
\text { criteria from } \\
\text { recent clinical } \\
\text { trials [16, 20] }\end{array}$ & $\begin{array}{l}\text { According } \\
\text { to EORTC/ } \\
\text { MSG 2002 [21] }\end{array}$ \\
\hline Proven & $3 / 57(5.3)$ & $2 / 57(3.5)$ & $2 / 57(3.5)$ \\
Probable & $26 / 57(45.6)$ & $35 / 57(61.4)$ & $4 / 57(7.0)$ \\
Possible & $14 / 57(24.6)$ & $1 / 57(1.8)$ & $32 / 57(56.1)$ \\
Not defined & $14 / 57(24.6)$ & $19 / 57(33.3)$ & $19 / 57(33.3)$ \\
\hline
\end{tabular}

Values in parenthesis are in percentage

investigator to rate evidence as probable without microbiological findings, the official criteria demand at least one microbiological criterion. Thus, 35 of the 57 cases with suspected or proven IFI had probable IFI according to the softer criteria, but only four patients had probable IFI when applying the official EORTC/MSG criteria. Independent of the applied edition of the EORTC/MSG criteria, 19 patients did not meet the requirements for classification of evidence even as possible (Table 3).

In the 21 patients, where voriconazole was given as empirical therapy, oral administration was preferred $(N=16)$. Average duration of fever was higher than in those with suspected or proven IFI, averaging 11.6 days. Treatment duration averaged 9.7 days, markedly shorter than the other subgroups. Eleven patients improved under empirical treatment, six were stable while four showed signs of progressive infection. There was a frequent switch of therapy to antifungals of different classes, i.e. liposomal amphotericin B $(N=3)$, caspofungin $(N=4)$ or their combination $(N=1)$ (Table 4).

Almost all patients on voriconazole as secondary prophylaxis $(N=19)$ received their treatment orally $(N=18)$. Mean treatment duration was 48.8 days. Four breakthrough IFIs were reported. Therapy was switched to other antifungals in seven cases, most often to caspofungin $(N=5)$ (Table 5).

The most frequent adverse events at least possibly related to voriconazole treatment by the investigators were visual disturbances $(N=6)$, nausea $(N=3)$ and rash $(N=3)$ (Table 6). At least one liver function test showed grade 3-4 toxicity, applying the common toxicity criteria in 15 cases, seven of which were attributed to voriconazole by the investigators. In this survey, gamma glutamyl transpeptidase was the most sensitive marker for voriconazole toxicity, showing a marked elevation in 12 cases of investigator attributed toxicity. However, no definite preference could be detected for any of the liver parameters assessed. None of the four patients with grade 3-4 nephrotoxicity were attributed to voriconazole (Table 6).
Table 4 Voriconazole dosing and treatment outcome

\begin{tabular}{|c|c|c|}
\hline & $\begin{array}{l}\text { Empirical } \\
\text { treatment } \\
(N=21)\end{array}$ & $\begin{array}{l}\text { Secondary } \\
\text { prophylaxis } \\
(N=19)\end{array}$ \\
\hline $\begin{array}{l}\text { Average initial } \\
\text { voriconazole dose in } \\
\mathrm{mg} / \mathrm{kg} \text { (range) }\end{array}$ & $5.7(2.469-10.870)$ & $5.7(3.3-7.5)$ \\
\hline \multicolumn{3}{|l|}{ Route of administration } \\
\hline Oral only & $16(76.2 \%)$ & $18(94.7 \%)$ \\
\hline Switch to oral & $2(9.5 \%)$ & 0 \\
\hline Switch to intravenous & - & $1(5.3 \%)$ \\
\hline Days with fever $( \pm \mathrm{SD})$ & $11.6( \pm 11.17)$ & n. a. \\
\hline $\begin{array}{l}\text { Days on antibiotic } \\
\text { treatment }( \pm \mathrm{SD})\end{array}$ & $29.8( \pm 13.55)$ & n. a. \\
\hline $\begin{array}{l}\text { Days on voriconazole } \\
\quad( \pm \text { SD })\end{array}$ & $9.7( \pm 6.94)$ & $48.8( \pm 84.31)$ \\
\hline Breakthrough IFI & n. a. & $4(21.1 \%)$ \\
\hline \multicolumn{3}{|l|}{ Outcome $^{a}$} \\
\hline Progressive disease & $4(19.1 \%)$ & n. a. \\
\hline Stable disease & $6(28.6 \%)$ & n. a. \\
\hline Partial response & $1(4.8 \%)$ & n. a. \\
\hline Complete response & $10(47.6 \%)$ & n. a. \\
\hline Switch to other antifungal & $8(38.1 \%)$ & $7(36.8 \%)$ \\
\hline Liposomal amphotericin B & $3(14.3 \%)$ & $2(10.1 \%)$ \\
\hline Caspofungin & $4(19.1 \%)$ & $5(26.3 \%)$ \\
\hline $\begin{array}{l}\text { Liposomal amphotericin } \\
\mathrm{B}+\text { caspofungin }\end{array}$ & $1(4.8 \%)$ & 0 \\
\hline
\end{tabular}

Table 5 Other adverse events $(N=100)$

\begin{tabular}{ll}
\hline Visual disturbance & 6 \\
Nausea & 3 \\
Rash & 3 \\
Hallucination & 2 \\
Vomiting & 2 \\
Diarrhea & 1 \\
Drug fever & 1 \\
Edema & 1 \\
\hline
\end{tabular}

Adverse events at least possibly related to voriconazole by judgment of the investigator

\section{Discussion}

In our survey, voriconazole was efficacious in $61.4 \%$ of patients treated for suspected or proven IFI (by assessment of the investigator). Favorable response was documented for $52.4 \%$ of patients receiving voriconazole as empirical therapy. This observation is comparable to prior results. For the treatment of suspected or proven IFI, especially IPA, investigator assessed favorable results defined as complete or partial responses were obtained in $61.4 \%$ as compared to $52.8 \%$ in Herbrecht's trial [16]. In the 
Table 6 Highest grade of treatment-emergent renal and hepatic adverse events
Values given in parenthesis are in percentage

${ }^{a}$ Toxicity judged at least possibly attributable to voriconazole treatment by the investigator

\begin{tabular}{llllll}
\hline CTC-toxicity [19] & Grade-1 $(\%)$ & Grade-2 $(\%)$ & Grade-3 $(\%)$ & Grade-4 (\%) & $N$ evaluable \\
\hline Liver & & & & & \\
GOT (AST) & $29(31.5)$ & $5(5.4)$ & $2(2.2)$ & $2(2.2)$ & 92 \\
& $6(6.5)^{\mathrm{a}}$ & $1(1.1)^{\mathrm{a}}$ & $1(1.1)^{\mathrm{a}}$ & $1(1.1)^{\mathrm{a}}$ & \\
GPT (ALT) & $20(20.2)$ & $4(4)$ & $1(1)$ & $1(1)$ & 99 \\
& $3(3)^{\mathrm{a}}$ & $3(3)^{\mathrm{a}}$ & $0(0)^{\mathrm{a}}$ & $1(1)^{\mathrm{a}}$ & \\
GGT & $14(15.7)$ & $14(15.7)$ & $11(12.4)$ & $0(0)$ & 89 \\
& $3(3.4)^{\mathrm{a}}$ & $4(4.5)^{\mathrm{a}}$ & $5(5.6)^{\mathrm{a}}$ & $0(0)^{\mathrm{a}}$ & \\
AP & $17(19.5)$ & $4(4.6)$ & $2(2.3)$ & $0(0)$ & 87 \\
& $7(8)^{\mathrm{a}}$ & $1(1.2)^{\mathrm{a}}$ & $1(1.2)^{\mathrm{a}}$ & $0(0)^{\mathrm{a}}$ & \\
Bilirubin & $10(11)$ & $5(5.5)$ & $4(4.4)$ & $2(2.2)$ & 91 \\
& $3(3.3)^{\mathrm{a}}$ & $3(3.3)^{\mathrm{a}}$ & $3(3.3)^{\mathrm{a}}$ & $1(1.1)^{\mathrm{a}}$ & \\
Kidney & $11(11)$ & $6(6)$ & & & \\
Creatinine & $2(2)^{\mathrm{a}}$ & $1(1)^{\mathrm{a}}$ & $0(0)^{\mathrm{a}}$ & $0(0)^{\mathrm{a}}$ & \\
& & & & \\
\hline
\end{tabular}

empirical setting, favorable response was reported in $52.4 \%$, while only a $26 \%$ overall response was reported previously [22]. However, the outcome evaluation was supposedly far more rigid in the clinical trials than the selfassessment of the registry contributors.

When compared to earlier prospective controlled clinical trials [16, 22], adverse events were less common. Visual disturbances were only reported in $6 \%$ and hallucinations in $2 \%$ as compared to 44.8 and $6.6 \%$, respectively, in aspergillosis [16] and to 21.9 and $4.3 \%$, respectively, in febrile neutropenia [22]. However, adverse event reporting is naturally less stringent in a survey than in controlled clinical trials.

Analysis of survey data did not reveal yet unknown toxicities of voriconazole. Treatment-related grade 3 or 4 hepatotoxicity was observed in 15 patients. Further frequent adverse events were visual disturbances (6\%), rash $(3 \%)$ and nausea $(3 \%)$.

Significant elevations of serum alkaline-phosphatase activities ( $>3 \times$ baseline value) occurred in $2.9 \%$ compared to $2.3 \%$ of grade 3-4 CTC toxicity in our study, aspartate aminotransferase ( $>3 \times$ baseline value) in 8.9 versus $4.4 \%$, alanine aminotransferase $(>3 \times$ baseline value) in 7.2 versus $2 \%$ and bilirubin $(\geq 1.5 \times$ baseline value $)$ in 27.2 versus $6.6 \%$ [22].

Our survey demonstrates that clinical reality regularly strays from approved indications and evidence based choice of treatment. A total of $43 \%$ of the reported patients received voriconazole prophylactically or empirically. One third of the 57 patients with voriconazole for treatment of actual IFI lacked sufficient evidence of IFI according to EORTC/MSG criteria [21]. Thus, a rate of as much as $62 \%$ may be considered as off-label use. Furthermore, all randomized controlled clinical trials on voriconazole used the intravenous formulation as initial treatment. Despite this,
$39.5 \%$ of patients with at least possible IFI were started on oral voriconazole. Looking at these figures, one could claim that only $23 \%$ of the patients reported were treated as approved by the German health administration and according to best scientific evidence. But does this mean patients were not treated in their best interest?

The difficulty of proving IFI remains a dilemma in choosing adequate treatment. There is still no sensitive and specific non-invasive method for detection of invasive pulmonary aspergillosis (IPA) [21, 23-25]. Controlled clinical trials on antifungal agents normally use the current EORTC/MSG criteria with or without modifications, while the consensus committee clearly discourages from clinical decision-making based on their guideline [21]. Additionally, especially in palliative situations, long-term inpatient treatment with intravenous antifungals is often undesirable. Finally, no antifungal has yet been approved for secondary prophylaxis of IPA.

In the above clinical situations, voriconazole offers a flexible and tolerable treatment option. Still, the many difficulties in the diagnosis and treatment of invasive fungal infections should not be used as a carte blanche in clinical decision making. Physicians should strive towards establishing the most accurate diagnosis possible and then treat according to current evidence.

Conflict of interest JJV has received travel grants from Merck, Pfizer, Schering-Plough, and Viropharma. DA, MK, MGK, KP, and $\mathrm{DR}$ declare no conflicts of interest. $\mathrm{AB}$ has received travel grants from, is an advisor to, or server at the speakers' bureau of Astellas, Basilea, Essex, Merck, Gilead, and Pfizer. AJU has received research grants from, is an advisor to, or served at the speakers' bureau of Astellas, Basilea, Gilead, Merck/MSD, Pfizer, Schering-Plough, and Stiefel. OAC is supported by the German Federal Ministry of Research and Education (BMBF grant 01KN0706) and has received research grants from, is an advisor to, or served at the speakers' bureau of Astellas, Basilea, Bayer, F2G, Genzyme, Gilead, Pfizer, 
Merck, Mölnlycke, Nektar, Schering-Plough, SpePharm, United Medical, Vicuron, and Zeneus.

\section{References}

1. Denning DW. Invasive aspergillosis. Clin Infect Dis. 1998;26(4):781-803; quiz 4-5.

2. Klimowski LL, Rotstein C, Cummings KM. Incidence of nosocomial aspergillosis in patients with leukemia over a 20-year period. Infect Control Hosp Epidemiol. 1989;10(7):299-305.

3. Rotstein C, Bow EJ, Laverdiere M, Ioannou S, Carr D, Moghaddam N. Randomized placebo-controlled trial of fluconazole prophylaxis for neutropenic cancer patients: benefit based on purpose and intensity of cytotoxic therapy. The Canadian Fluconazole Prophylaxis Study Group. Clin Infect Dis. 1999;28(2):331-40.

4. Winston DJ, Chandrasekar PH, Lazarus HM, Goodman JL, Silber JL, Horowitz H, et al. Fluconazole prophylaxis of fungal infections in patients with acute leukemia. Results of a randomized placebo-controlled, double-blind, multicenter trial. Ann Intern Med. 1993;118(7):495-503.

5. Pfaller MA, Diekema DJ, Messer SA, Boyken L, Hollis RJ, Jones RN. In vitro activities of voriconazole, posaconazole, and four licensed systemic antifungal agents against Candida species infrequently isolated from blood. J Clin Microbiol. 2003;41(1):78-83.

6. Pfaller MA, Messer SA, Hollis RJ, Jones RN, Doern GV, Brandt $\mathrm{ME}$, et al. In vitro susceptibilities of Candida bloodstream isolates to the new triazole antifungal agents BMS-207147, Sch 56592, and voriconazole. Antimicrob Agents Chemother. 1998;42(12):3242-4.

7. Pfaller MA, Messer SA, Boyken L, Hollis RJ, Rice C, Tendolkar $\mathrm{S}$, et al. In vitro activities of voriconazole, posaconazole, and fluconazole against 4,169 clinical isolates of Candida spp. and Cryptococcus neoformans collected during 2001 and 2002 in the ARTEMIS global antifungal surveillance program. Diagn Microbiol Infect Dis. 2004;48(3):201-5.

8. Johnson EM, Szekely A, Warnock DW. In-vitro activity of voriconazole, itraconazole and amphotericin $\mathrm{B}$ against filamentous fungi. J Antimicrob Chemother. 1998;42(6):741-5.

9. Manavathu EK, Cutright JL, Chandrasekar PH. Organismdependent fungicidal activities of azoles. Antimicrob Agents Chemother. 1998;42(11):3018-21.

10. Linares MJ, Charriel G, Solis F, Rodriguez F, Ibarra A, Casal M. Susceptibility of filamentous fungi to voriconazole tested by two microdilution methods. J Clin Microbiol. 2005;43(1):250-3.

11. Arikan S, Lozano-Chiu M, Paetznick V, Nangia S, Rex JH. Microdilution susceptibility testing of amphotericin B, itraconazole, and voriconazole against clinical isolates of Aspergillus and Fusarium species. J Clin Microbiol. 1999;37(12):3946-51.
12. Espinel-Ingroff A. In vitro activity of the new triazole voriconazole (UK-109, 496) against opportunistic filamentous and dimorphic fungi and common and emerging yeast pathogens. J Clin Microbiol. 1998;36(1):198-202.

13. Clancy CJ, Nguyen MH. In vitro efficacy and fungicidal activity of voriconazole against Aspergillus and Fusarium species. Eur J Clin Microbiol Infect Dis. 1998;17(8):573-5.

14. Espinel-Ingroff A. In vitro fungicidal activities of voriconazole, itraconazole, and amphotericin B against opportunistic moniliaceous and dematiaceous fungi. J Clin Microbiol. 2001;39(3):9548.

15. Gonzalez GM, Fothergill AW, Sutton DA, Rinaldi MG, Loebenberg D. In vitro activities of new and established triazoles against opportunistic filamentous and dimorphic fungi. Med Mycol. 2005;43(3):281-4.

16. Herbrecht R, Denning DW, Patterson TF, Bennett JE, Greene RE, Oestmann J-W, et al. Voriconazole versus amphotericin B for primary therapy of invasive aspergillosis. N Engl J Med 2002;347(6):408-15.

17. Pfizer Inc. N. label information: VFEND (voriconazole). New York: Pfizer Inc.; 2006.

18. Bohme A, Ruhnke M, Buchheidt D, Karthaus M, Einsele H, Guth $\mathrm{S}$, et al. Treatment of fungal infections in hematology and oncology-guidelines of the infectious diseases working party (AGIHO) of the German society of hematology and oncology (DGHO). Ann Hematol. 2003;82(Suppl 2):S133-40.

19. NCI, DCTD, NIH, DHHS. Common toxicity criteria version 2.0. Bethesda: National Institutes of Health; 1999.

20. Cornely OA, Maertens J, Bresnik M, Herbrecht R. Liposomal amphotericin B as initial therapy for invasive filamentous fungal infections: a randomized, prospective trial of a high loading regimen versus a standard dosing (AmBiLOAD Trial). Blood. 2005;106(11):900a.

21. Ascioglu S, Rex JH, de Pauw B, Bennett JE, Bille J, Crokaert F, et al. Defining opportunistic invasive fungal infections in immunocompromised patients with cancer and hematopoietic stem cell transplants: an international consensus. Clin Infect Dis. 2002;34(1):7-14.

22. Walsh TJ, Pappas P, Winston DJ, Lazarus HM, Petersen F, Raffalli J, et al. Voriconazole compared with liposomal amphotericin B for empirical antifungal therapy in patients with neutropenia and persistent fever. $\mathrm{N}$ Engl $\mathrm{J}$ Med. 2002;346(4):225-34.

23. Pfeiffer CD, Fine JP, Safdar N. Diagnosis of invasive aspergillosis using a galactomannan assay: a meta-analysis. Clin Infect Dis. 2006;42(10):1417-727.

24. Ferns RB. Evaluation of the role of real-time PCR in the diagnosis of invasive aspergillosis. Leuk Lymphoma. 2006;47(1):1520.

25. Karthaus M, Cornely OA. Recent developments in the management of invasive fungal infections in patients with hematological malignancies. Ann Hematol. 2005;84(4):207-16. 